\title{
Mitigating the conflict between pitfall-trap sampling and conservation of terrestrial subterranean communities in caves
}

\author{
${\text { Peter Kozel }{ }^{*} \text {, Tanja Pipan }}^{1}$, Nina Šajna², Slavko Polak ${ }^{3}$, and Tone Novak ${ }^{2}$ \\ ${ }^{1}$ Karst Research Institute, Research Centre of the Slovenian Academy of Sciences and Arts, Titov trg 2, SI-6230 Postojna, Slovenia \\ and UNESCO Chair on Karst Education, University of Nova Gorica, Glavni trg 8, SI-5271Vipava, Slovenia \\ ${ }^{2}$ Department of Biology, Faculty of Natural Sciences and Mathematics, University of Maribor, Koroška cesta 160, SI-2000 Maribor, Slovenia \\ ${ }^{3}$ Zavod Znanje, OE Notranjska Museum Postojna, Kolodvorska cesta 3, SI-6230 Postojna, Slovenia
}

\begin{abstract}
Subterranean habitats are known for their rich endemic fauna and high vulnerability to disturbance. Many methods and techniques are used to sample the biodiversity of terrestrial invertebrate fauna in caves, among which pitfall trapping remains one of the most frequently used and effective ones. However, this method has turned out to be harmful to subterranean communities if applied inappropriately. Traditionally, pitfall traps have been placed in caves solely on the ground. Here we present an optimized technique of pitfall trapping to achieve a balance between sampling completeness and minimal disturbance of the fauna in the cave. Monthly we placed traps for two days in two parallel sets, a ground trap and an upper one-just below the ceiling-along the cave. In the upper set, about $10 \%$ additional species were recorded compared to the ground set. Greater species diversity in the cave was the consequence of both the increased sampling effort and the amplified heterogeneity of sampled microhabitats. In caves sampled by traditional pitfall trapping, overlooked species may be a consequence of methodological biases, leading to lower biodiversity estimates. In our research, incidencebased estimations mostly surpassed abundance-based ones and predicted $95 \%$ coverage of the species richness within about two years of sampling. The sampling used contributes at the same time to both the more effective and less invasive inventory of the subterranean fauna. Thus, it may serve as an optional sampling to achieve optimal balance between required data for biodiversity and ecological studies, and nature conservation goals.
\end{abstract}

Keywords: $\quad$ biological inventories, biodiversity estimators, microhabitats, sampling effort, sampling techniques Received 17 March 2017; Revised 9 May 2017; Accepted 10 May 2017

Citation: $\quad$ Kozel P., Pipan T., Šajna N., Polak S. and Novak T., 2017. Mitigating the conflict between pitfall-trap sampling and conservation of terrestrial subterranean communities in caves. International Journal of Speleology, 46 (3), 359-368. Tampa, FL (USA) ISSN 0392-6672 https://doi.org/10.5038/1827-806X.46.3.2123

\section{INTRODUCTION}

In recent decades, in light of serious concerns about rapid biodiversity loss and a crisis in biodiversity knowledge, considerable efforts have been devoted to measuring and documenting global biodiversity (Mooney \& Mace, 2009; Krauss et al., 2010; Mora et al., 2011). However, it is often time-consuming and laborious to perform representative sampling of species communities, especially in the case of invertebrates (Żmihorski et al., 2013). In subterranean terrestrial fauna, this is true for two main reasons: the large number of endemic species and the high susceptibility of subterranean fauna to disturbance. Research into subterranean fauna biodiversity (e.g., Deharveng et al., 2000; Christman et al., 2005; Trontelj et al., 2009; Niemiller \& Zigler, 2013) has been conspicuously related to efforts to provide optimal biodiversity data.
Although caves and other subterranean habitats are usually considered among the most extreme environments on the planet (Howarth, 1993; Fišer et al., 2012) their fauna is diverse (e.g., Culver \& Sket, 2000; Culver \& Pipan, 2009, 2013; Reboleira et al., 2011; Sket, 2012; Souza Silva \& Ferreira, 2016). Significant progress on biodiversity patterns has been done in the last decade (e.g., Zagmajster et al. 2008, 2010; Malard et al., 2009; Culver et al., 2013; Niemiller \& Zigler, 2013; Bregovič \& Zagmajster, 2016). Despite all these efforts, scientific sampling of terrestrial fauna biodiversity in caves has been only rarely evaluated for effectiveness (e.g., Weinstein \& Slaney, 1995; Bichuette et al., 2015).

Besides observation and manual collection, baited pitfall trapping has been the most frequently applied method for sampling terrestrial invertebrates in caves (Peck, 1995; Slaney \& Weinstein, 1996; Hunt \& 
Millar, 2001; Campbell et al., 2011). The method is cheap, simple to use, requires little labor and yields greater numbers of individuals belonging to a wide range of taxa (Ward et al., 2001), and is therefore popular among ecologists (Sabu \& Shiju, 2010; Tista \& Fiedler, 2011; Żmihorski et al., 2013). Baited pitfall traps provide results that differ in comparison to other methods (Weinstein \& Slaney, 1995). Such traps attract, among others, organisms from fissures, which are likely the primary habitat for many species in caves (Juberthie, 1969; Kuštor \& Novak, 1980; Culver \& Pipan, 2009). Animals are probably attracted from greater distances (Poulson \& Culver, 1968; Juberthie, 1969). On the other hand, pitfall trapping has long been known to cause population reduction in caves (Vandel, 1965; Howarth, 1981). Especially longterm systematic trapping repeated at the same sites, or traps forgotten in caves, can be very deleterious because of oversampling and depletion of populations of some taxa (Sharratt et al., 2000; Cardoso, 2012). In subterranean habitats, this is especially important for protected and vulnerable taxa, generally with limited populations (Hunt \& Millar, 2001; Cardoso, 2012). When applying pitfall trapping, prudent consideration is required, as the collecting should be kept to a minimum (Culver \& Pipan, 2009).

Scientists frequently encounter a conflict between collecting and conservation of taxa (Henen, 2016), even though biological inventories provide the foundation for improving the applied pursuit of sustainable resource management and conservation (Magurran, 1996). Scientific collecting and conservation efforts should aim to be synergistic and productive, rather than contradictory (Henen, 2016). It is thus indispensable to improve sampling methods and procedures, to devise and implement new ones and find the optimal balance between collecting for scientific purposes and conservation (Minteer et al., 2014).

Investigators applying pitfall traps in caves are mostly exploiting linear transect within caves, or they may investigate specific sites or cave sections of interest (Juberthie, 1969; Shaw \& Davis, 1999; Novak et al., 2004, 2012; Campbell et al., 2011; Mammola et al., 2015). The traps are placed on the ground either in groups or in transects. The vertical distribution and dynamics of fauna have only rarely been taken into account in caves (e.g., Novak et al., 2010; Mammola \& Isaia, 2016; Mammola et al., 2016). Some species distributions in caves are influenced by microhabitat distribution, even, e.g., by the structural heterogeneity of cave walls (Bourne, 1967; Mammola \& Isaia, 2016; Mammola et al., 2016); therefore, various microhabitats should also be considered in such studies.

In this study, our main concern was the optimization of pitfall sampling in caves, one of the most frequently used methods for studies of biodiversity and community ecology, which in turn often provide a basis for faunal conservation. Consequently, our study includes two of the most important issues in the conflict between scientific collection and conservation of subterranean communities: 1) credible coverage of various microhabitats within a cave, and 2) as little invasive sampling as possible. In this respect, the cave floor and the ceiling constitute two of the potentially most distinct types of microhabitats. Besides, multiple data on species incidence, i.e., presence of a species in a particular place and time (e.g., Novak et al., 2012), may considerably lower the number of sampled individuals required for reliable biodiversity estimations.

We thus address two main questions: 1) Whether combined sampling, i.e., parallel ground and wall and ceiling sampling, provides greater species richness outcomes in comparison with an equally large traditional sample, i.e., ground only pitfall trap sampling 2) Which approach-the incidence-based approach or the abundance-based approach-is more efficient and provides more robust estimates of species richness. To this end, we simultaneously focused on the question of whether increased sampling effort alone is responsible for the additional species collected, or whether it could be the consequence of an enlarged set of various microhabitats. These issues could mitigate the conflict between scientific sampling and conservation of fauna in caves.

\section{MATERIALS AND METHODS}

\section{Study site}

The study was performed in the cave Zguba jama (Cadastre number 6290, Cave Register of the Karst Research Institute ZRC SAZU and Speleological Association of Slovenia) in the vicinity of Postojna (Fig. 1). The cave is a potential fossil continuation of the Pisani rov passage in Postojnska jama (Šebela, 1994). The entrance of Zguba jama is located at $561 \mathrm{~m}$ a.s.1. This cave (122 $\mathrm{m}$ long and $4 \mathrm{~m}$ deep) has an entrance $1.5 \mathrm{~m}$ wide and $1 \mathrm{~m}$ high. Cave cross sections (width $\mathrm{x}$ height) measure $0.9-2 \times 0.5-2.5 \mathrm{~m}$, with few sites where the ceiling reaches $5 \mathrm{~m}$ high. Such morphology enabled relatively easy setting of pitfall traps beneath the ceiling (Fig. 2).

\section{Sampling design}

Terrestrial fauna was sampled by baited pitfall traps. Along the cave passage, 31 sampling sites were located about $4 \mathrm{~m}$ apart (Fig. 2). We used $85 \mathrm{~mm}$ deep plastic cups, with a rim diameter of $56 \mathrm{~mm}$. For bait, we used decomposing beef (1.5 g; wrapped in gauze, left in a closed glass for 4-5 days at room temperature to become tainted, and attached by a wire in the middle of the cup opening) and apple juice with a lacing of cherry and maraschino essence, ca. $2 \mathrm{~cm}$ deep in the cup. Additionally, a few drops of detergent were added to reduce the surface tension. Pitfall traps were placed in two parallel sets, the upper set -just below the ceiling- and the ground set along the cave (Fig. 3). The upper traps were affixed with a plasticized wire to wall or ceiling features (e.g., holes, small speleothems and fissures) above the ground traps. In smooth walls, we drilled small holes and used stainless steel screws to hang the traps. In cave sections lower than $2 \mathrm{~m}$, the upper traps were set just below the ceiling, while in higher sections these were set $2 \mathrm{~m}$ above the floor on the wall. About one half of the trap mouth was 

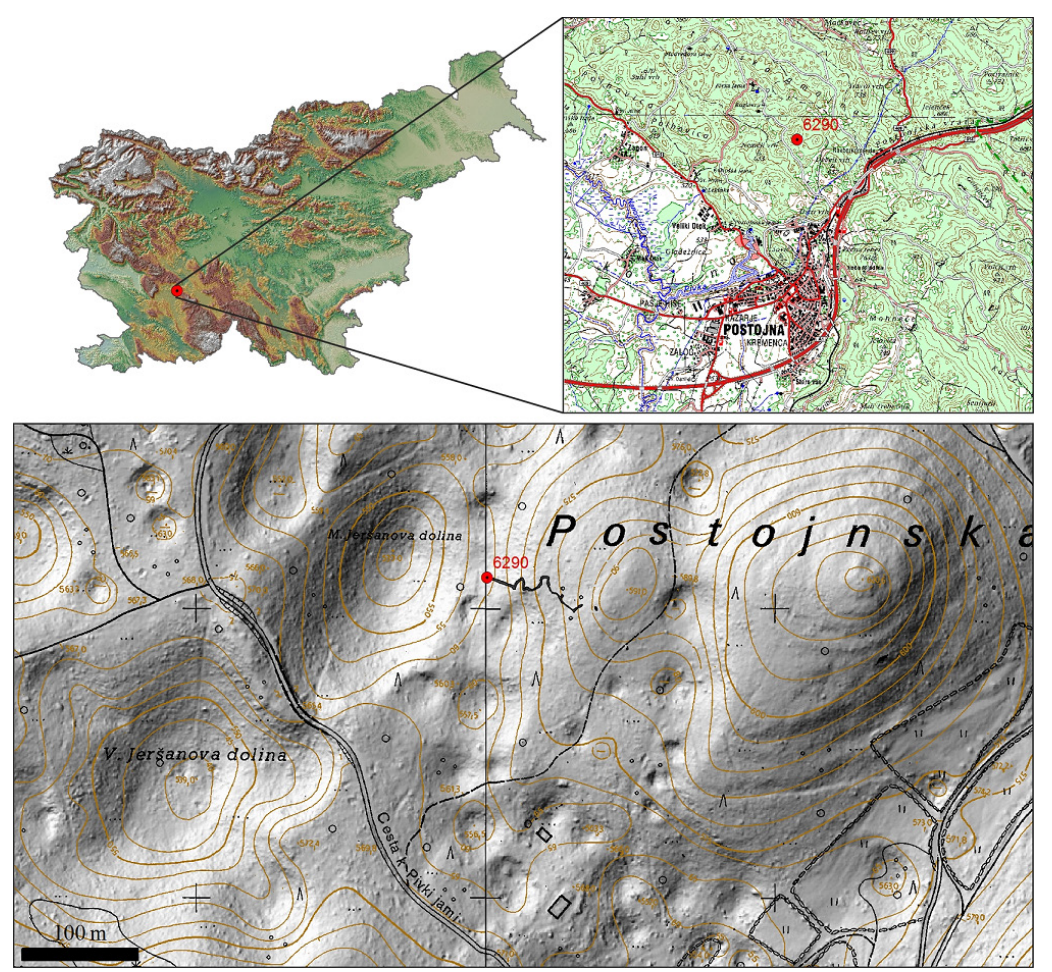

Fig. 1. Geographical location of the study site (source: LIDAR DEM, Cave Register 2016, TTN5).
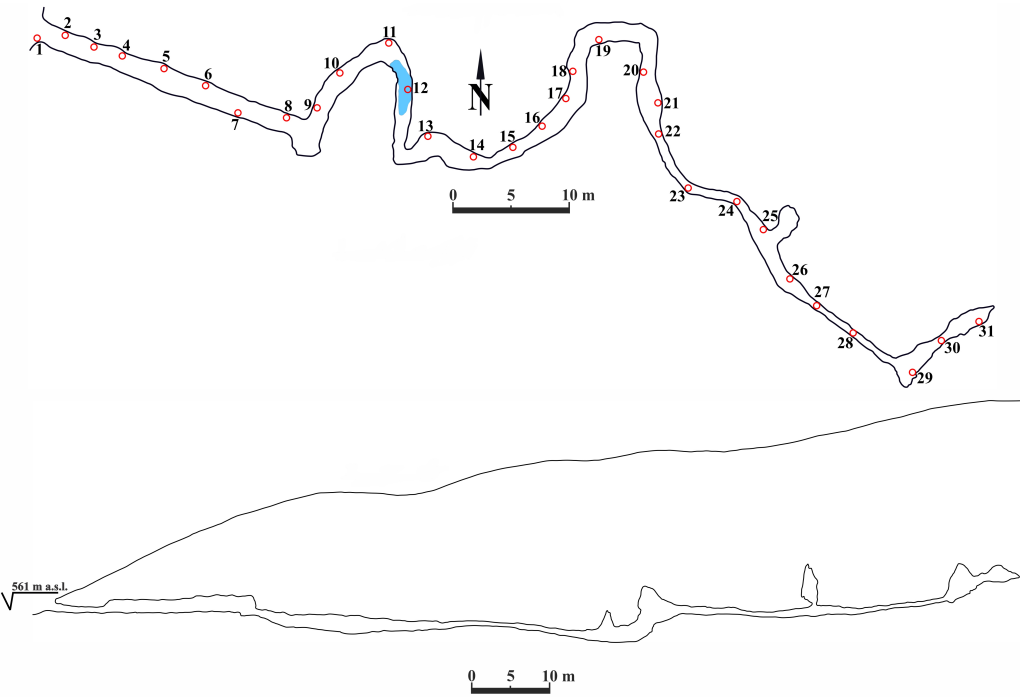

Fig. 2. Ground plan and longitudinal section of Zguba jama, with marked sampling sites (plan according to Šebela, 1994).

attached to the ceiling using clay to fill any gaps between the trap and the ceiling. Ground traps were buried in the substrate, with the entire cup mouth level with the substrate, and shored up with small stones and clay where necessary. Monthly sampling of the terrestrial fauna lasted for one year and started began in March 2012 and finished in February 2013. It was carried out in two visits per month-for placing and collecting the traps-within about 48 hours, in accordance with the finding that such sampling could provide credible data for statistical analysis and simultaneously avoid population depletion (Novak et al., 2012). The collected fauna was identified within two days and preserved in $70 \%$ ethanol. Voucher specimens are deposited at the Karst Research Institute, Postojna, and the
Faculty of Natural Sciences and Mathematics, University of Maribor.

Regarding the general ecological classification of subterranean fauna (Schiner, 1854; Racoviță, 1907; Boutin, 2004; Culver \& Pipan, 2009, 2014; Novak et al., 2012), we use the following categories: trogloxenes - species not adapted to the subterranean environment, troglophiles species partly adapted, and troglobionts - species well adapted to the subterranean environment (i.e., obligate subterranean dwellers).

\section{Data analysis}

For the analyses, we arranged three datasets: the ground, upper and the combined groundupper sets, the last one comprising the two previous sets. Consequently, the ground-upper set involved twice the number of sampling sites compared with both the ground and the upper sets.

Annual counts and species richness for each sampling site were used to calculate the Shannon-Weaver index $\left(\mathrm{H}^{\prime}\right)$ separately for the ground and the upper pitfall trap sets, using the vegan $\mathrm{R}$ package (Oksanen et al., 2016). This index was employed because it downweights very rare and very numerous species and is more affected by individual counts as measures of relative abundance than by true abundance (Sager \& Hasler, 1969). In this way, standardized diversities with different absolute abundances (Tobin et al., 2013) were compared for the two sets. Data normality was graphically evaluated by means of histograms and QQ-plots, as suggested by Zuur et al. (2010). Spearman rank correlation coefficient $\left(\mathrm{r}_{\mathrm{s}}\right)$ was calculated for the abundance vs. richness, abundance vs. diversity, and richness vs. diversity for both trap sets. Differences between counts, richness and diversity for both pitfall sets were tested using the Mann-Whitney-Wilcoxon Test.

The iNEXT function from the iNEXTR package (Hsieh et al., 2016) was applied to compute and
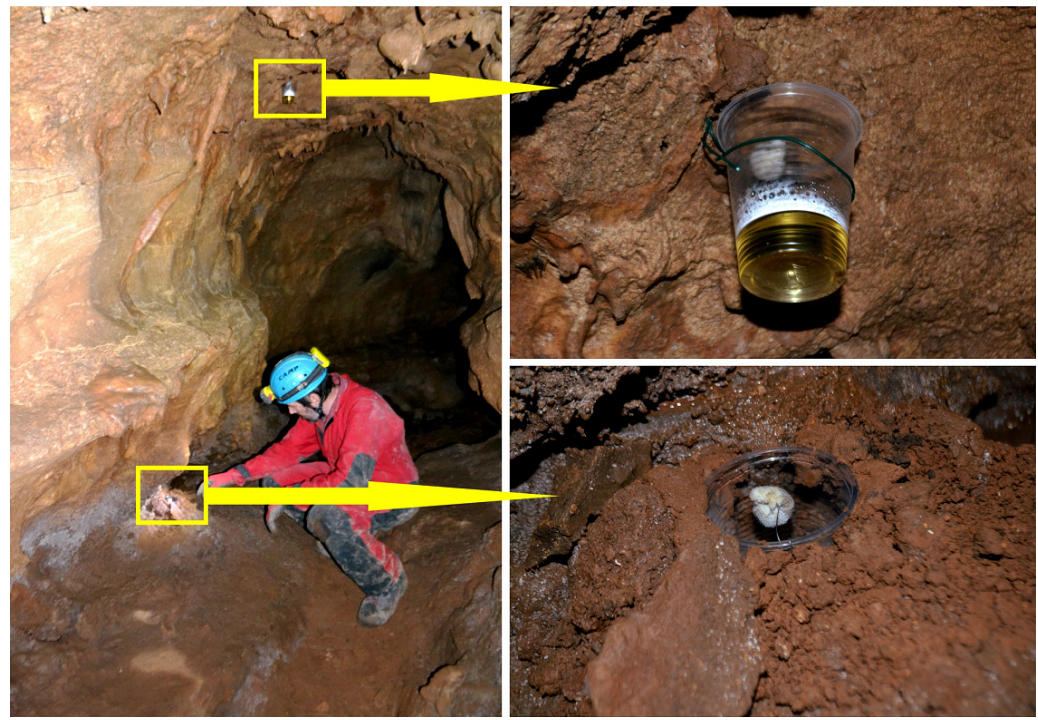

Fig. 3. Setting of the upper and the ground pitfall traps at a sampling site. 
plot the rarefaction and extrapolation sampling curves of species richness for individual-based abundance data and sampling-based incidence data for the upper, ground and upper-ground set. Bootstrap confidence intervals, specifying 100 bootstrap replications (Chao et al. 2016b), for rarefied/extrapolated samples were added, facilitating the comparison of diversity across assemblages (Chao et al., 2014; Hsieh et al., 2016). Rarefaction curves were calculated to provide evidence of whether the ground-upper sampling was more efficient than a single-set-alone sampling. We applied extrapolation of the reference sample to check whether the doubled quantity of the upper and ground samples separately would provide an equivalent to the combined upper-ground sampling. Applying the ChaoSpecies function of the SpadeR R package (Chao et al., 2016a), several non-parametric estimators were calculated for all three sets in order to determine whether the combined ground-upper sampling predicted greater total species richness estimations than the traditional, ground-only sampling. We used counts of individuals as an estimate of relative abundance, based on our long-term sampling, in order to generate our abundance-based estimates of species richness. Estimates of species richness can strongly be dependent on differences in inventory completeness (Brose et al., 2003; Chao \& Jost, 2012). Therefore, we estimated inventory completeness using the sample coverage estimator (Hsieh et al., 2016).

To test whether microhabitat specifics were affecting species distribution, we considered two types of beta diversity. Beta diversity can be the result of species replacement between sites (turnover) or species loss from site to site (nestedness), and allows inferences about the processes driving species distribution and biodiversity (Baselga \& Orme, 2012). We calculated pairwise between-site partitions of beta diversity for the upper and ground trap sites, using the beta. pair function from the betapart $\mathrm{R}$ package (Baselga et al., 2013). This pairwise partition was tested using the Mann-Whitney-Wilcoxon Test. All analyses were performed in R (R Development Core Team, 2016).

Using the Excel spreadsheet macro provided by Chao et al. (2009), we calculated the necessary sampling effort for both the number of individuals and the number of samples, to collect 95\%, 99\%, and $100 \%$ of the estimated number of species within the assemblage. In these calculations, the number of undetected species can be assessed on the basis of the number of singletons (species represented by one individual), doubletons (species represented by two individuals), uniques (species occurring in only one sample, but potentially with more than one individual) and duplicates (species occurring in only two samples) (see Chao et al., 2009; Gotelli \& Colwell, 2011).

\section{RESULTS}

In the cave we collected 2810 individuals from 744 pitfall-trap samples belonging to 88 arthropod species, most of which (48 species; 55\%) were insects. The most numerous taxa, i.e., those with $>100$ individuals, were Onychiuroides postumicus (Collembola: Onychiuridae) (936 individuals; 33.3\%), Phoridae sp.1 (Diptera) (310 ind.; 11.0\%), Absolonia gigantea (Collembola: Onychiuridae) (131 ind.; 4.7\%) and Sciaridae sp. 1 (Diptera) (107 ind.; 3.8\%). We also recorded 17 species represented by a single individual, all of them trogloxenes. Each higher taxon that was not determined to the species level was considered a further species. Trogloxenes were most abundant with 65 species, followed by troglobionts with 14, and troglophiles with nine species.

In the ground traps we collected $89.7 \%$, and in the upper traps $61.4 \%$ of the total species recorded. Nearly two thirds $(64.6 \%)$ of individuals were in the ground traps (Table 1). Certain taxa were collected exclusively either in the upper or in the ground traps. Nine species $(10.2 \%)$, all trogloxenes, were found only in the upper traps: Isopoda sp. 1, Trachelipus rathkii (Isopoda: Trachelipodidae), Necrophorus vespilloides (Coleoptera: Silphidae), Staphylinidae sp. 1 (Coleoptera), Diptera sp.1, Lucilia sp. 1 (Diptera: Calliphoridae), Trichocera hiemalis (Diptera: Trichoceridae), Mymaridae sp.1 (Hymenoptera) and Microlepidoptera sp. 1. These species contributed to greater overall species richness in the cave.

Annual counts, species richness and ShannonWeaver indices for the ground and the upper trap sets are presented in Figure 4. In both sets of pitfall

Table 1. Annual observed and estimated richness and sampling efforts for abundance-based and incidence-based estimators in Zguba jama from March 2012 till February 2013. $n$ - number of individuals collected; $t$ - number of samples collected; $T$ - total number of incidences; $\mathrm{S}_{\mathrm{obs}}-$ observed species richness; $\mathrm{S}_{\text {est }}$ - estimated asymptotic species richness based on Chao1 for abundance-based data and on Chao2 for incidence-based data; SC - sample coverage (percentage of the total number of individuals in an assemblage that belong to the species represented in the sample); $f_{1}$ - number of singletons; $f_{2}$ - number of doubletons; $Q_{1}$ - number of uniques; $Q_{2}-$ number of duplicates; $q_{0}-$ the probability that the next individual/ sample represents a previously undetected species; $g$ - number of additional individuals required to reach $100 \%(g=1), 99 \%(g=0.99)$, and $95 \%$ $(\mathrm{g}=0.95) \mathrm{S}_{\text {est }}$, respectively.

\begin{tabular}{|c|c|c|c|c|c|c|c|c|c|c|c|}
\hline \multicolumn{12}{|c|}{ Abundance-based data } \\
\hline & $n$ & $\mathbf{S}_{\text {obs }}$ & $\mathbf{S}_{\text {est }}$ & SC & $f_{1}$ & $f_{2}$ & $q_{o}$ & \multicolumn{2}{|c|}{$g=1$} & $g=0.99$ & $g=0.95$ \\
\hline Ground & 1815 & 79 & 86 & 99.1 & 16 & 19 & 0.009 & \multicolumn{2}{|c|}{3465} & 1575 & 345 \\
\hline Upper & 995 & 54 & 68 & 98.7 & 13 & 6 & 0.013 & \multicolumn{2}{|c|}{5541} & 3265 & 1531 \\
\hline Ground-Upper & 2810 & 88 & 97 & 99.4 & 17 & 17 & 0.006 & \multicolumn{2}{|c|}{6664} & 3058 & 796 \\
\hline \multicolumn{12}{|c|}{ Incidence-based data } \\
\hline & $\boldsymbol{t}$ & $T$ & $\mathbf{S}_{\text {obs }}$ & $\mathbf{S}_{\text {est }}$ & SC & $Q_{1}$ & $Q_{2}$ & $q_{o}$ & $g=1$ & $g=0.99$ & $g=0.95$ \\
\hline Ground & 372 & 744 & 79 & 100 & 96.4 & 27 & 17 & 0.036 & 1685 & 903 & 428 \\
\hline Upper & 372 & 443 & 54 & 84 & 95.7 & 19 & 6 & 0.043 & 3522 & 2102 & 1156 \\
\hline Ground-Upper & 372 & 1187 & 88 & 110 & 97.8 & 28 & 18 & 0.024 & 1657 & 863 & 397 \\
\hline
\end{tabular}



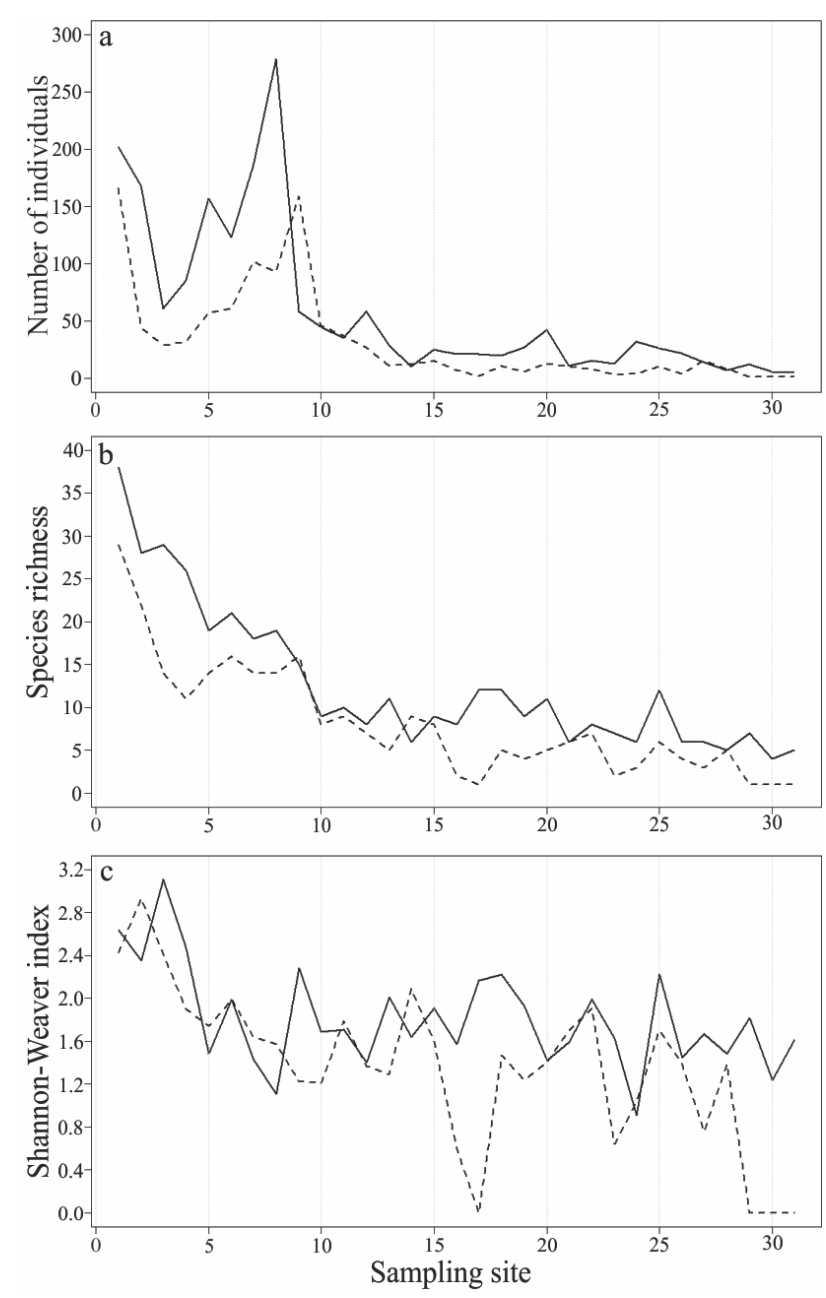

Fig. 4. Total annual individual counts (a), species richness (b) and Shannon-Weaver index (c) for the ground (solid line) and the upper (dashed line) pitfall trap sets.

traps, these three parameters exponentially declined from the entrance inward, with a conspicuous peak in individuals counts about $20-30 \mathrm{~m}$ inside. On average, 58.5 individuals and 12.6 species per ground trap, and 32.1 individuals and 8.1 species per upper trap were recorded. The average $\mathrm{H}^{\prime}$ per ground trap was 1.81, and per upper trap, 1.37. Counts $(\mathrm{W}=648$, $\mathrm{p}=0.02)$, species richness $(\mathrm{W}=662.5, \mathrm{p}=0.01)$ and diversity ( $\mathrm{W}=664, \mathrm{p}=0.01)$ were significantly greater in the ground set.

For the upper traps, correlations in abundancerichness, abundance-diversity, and richness-diversity $\left(r_{s}=0.92, p<0.01 ; r_{s}=0.63, p<0.01 ; r_{s}=0.83, p<0.01\right.$, respectively) were greater than correlations for ground traps $\left(\mathrm{r}_{\mathrm{s}}=0.85, \mathrm{p}<0.01 ; \mathrm{r}_{\mathrm{s}}=0.19, \mathrm{p}=0.29\right.$; $\left.r_{s}=0.58, p<0.01\right)$. All pairwise correlations, except abundance-diversity for the ground traps, were statistically significant.

Sample coverage was nearly the same for all three sets for both, the abundance-based and the incidence-based data (Table 1), indicating that we collected between 95.7 and $99.4 \%$ species. This enables comparison of the three sets and suggests that species richness was not biased by differences in sample coverage among the sets. The probability that an additional individual and sample would provide further, previously unrecorded species, was greatest for the upper set and lowest for the combined ground-upper set (Table 1).
In both the abundance and the incidence approaches, the rarefaction and extrapolation curves of species richness for the ground and the groundupper sets substantially overlap, while the upper-set curve shows lower values (Fig. 5). However, the upperground set evidences additional species with respect to the ground set. In the abundance approach, the species richness obtained by extrapolated doubled ground sampling does not reach the observed species richness in the upper-ground set (Fig. 5). In the incidence approach, the species richness obtained by extrapolated doubled ground sampling exceeds the species richness of the observed ground-upper sampling. However, fourfold extrapolated ground sampling does not approach doubled upper-ground sampling, indicating that the upper microhabitats do contribute additional species. In the upper trap set, beta diversity among sites was significantly greater in comparison to the ground set (Table 2), suggesting greater heterogeneity of microhabitats in the upper set.

Non-parametric species richness estimators proposed between 59.2 and $93.6 \%$ species recorded in all the sets (Table 3). Overall, the greatest estimates were achieved for the combined upper-ground set. Moreover, incidence-based estimates mostly surpassed the abundance-based ones.

\section{DISCUSSION}

The main purpose of biological monitoring in caves is to assess the current state of particular subterranean habitats and to make an inventory of animals that
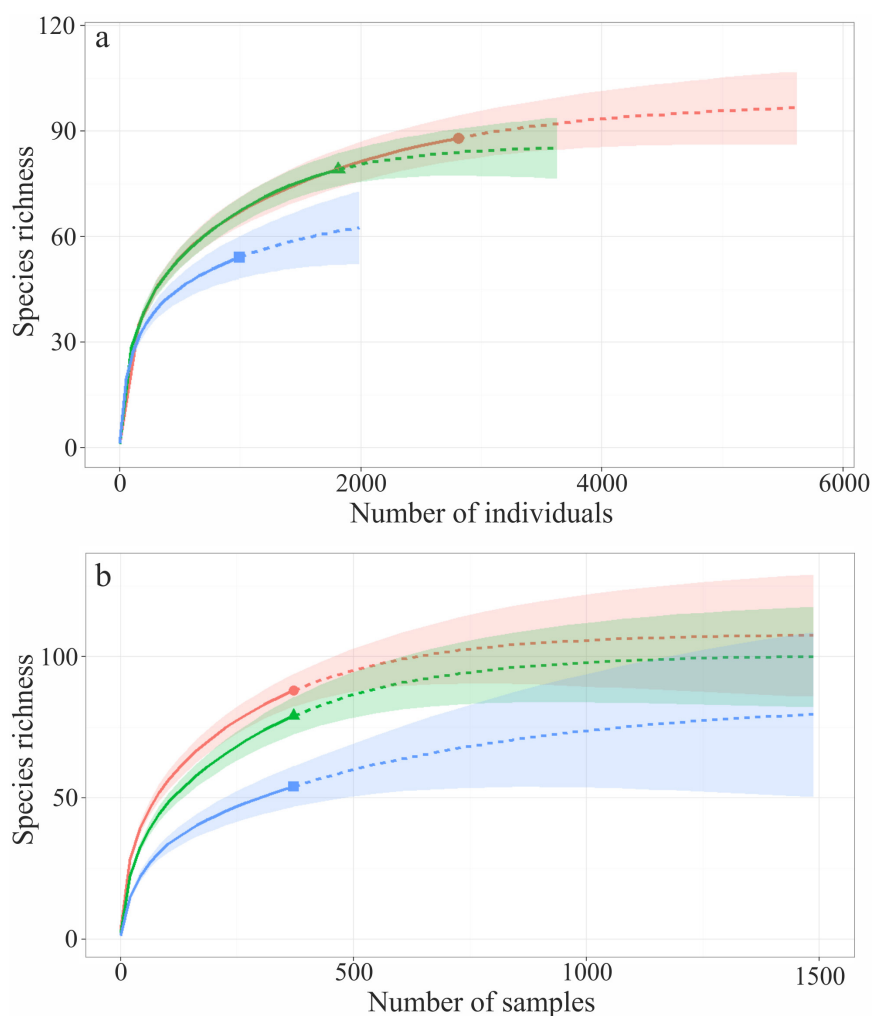

Fig. 5. Rarefaction and extrapolation curves of species richness for three pitfall trap sets for the individual-based abundance data (a) and sampling-based incidence data (b), with $95 \%$ bootstrap confidence intervals indicated. Rarefaction - solid lines; extrapolation - up to the double reference sample size - dashed lines; upper set - blue, ground set - green, ground-upper set - red. 
Table 2. The pairwise between-site partitions of beta diversity for Ground and Upper sites, and the Mann-Whitney-Wilcoxon Test of significance.

\begin{tabular}{|l|c|c|c|}
\cline { 2 - 4 } \multicolumn{1}{c|}{} & Ground mean $\mathbf{~ S D ~}$ & Upper mean \pm SD & p-value \\
\hline Sørensen dissimilarity & $0.66 \pm 0.18$ & $0.73 \pm 0.21$ & $<\mathbf{0 1}$ \\
\hline Sørensen turnover & $0.52 \pm 0.20$ & $0.55 \pm 0.31$ & 0.07 \\
\hline Sørensen nestedness & $0.13 \pm 0.10$ & $0.18 \pm 0.21$ & 0.63 \\
\hline Jaccard dissimilarity & $0.78 \pm 0.13$ & $0.83 \pm 0.16$ & $<\mathbf{0 1}$ \\
\hline Jaccard turnover & $0.66 \pm 0.18$ & $0.65 \pm 0.30$ & 0.06 \\
\hline Jaccard nestedness & $0.12 \pm 0.10$ & $0.18 \pm 0.24$ & 0.85 \\
\hline
\end{tabular}

Table 3. Total species richness estimated (Est) by different non-parametric methods for the upper, ground and the ground-upper sets using abundance and incidence data. SE - standard error; $\mathrm{Cl}$ - confidence interval; \% - estimated percentage of species recorded (species sampled/species estimated $\times 100)$.

\begin{tabular}{|c|c|c|c|c|c|c|c|c|c|c|}
\hline \multirow{2}{*}{$\frac{\text { Estimator/Model }}{\text { Ground }}$} & \multicolumn{5}{|c|}{ Abundance data } & \multirow[b]{2}{*}{ Est } & \multicolumn{4}{|c|}{ Incidence data } \\
\hline & Est & SE & \multicolumn{2}{|c|}{$95 \% \mathrm{CI}$} & $\%$ & & $\mathbf{S E}$ & \multicolumn{2}{|c|}{$95 \% \mathrm{CI}$} & $\%$ \\
\hline Homogeneous Model & 84.8 & 3.1 & 81.1 & 94.7 & 93.6 & 90.1 & 4.8 & 83.9 & 103.9 & 87.7 \\
\hline Chao1 & 85.7 & 4.5 & 81.0 & 101.3 & 92.2 & & & & & \\
\hline Chao1-bc & 85.0 & 4.2 & 80.8 & 99.5 & 92.9 & & & & & \\
\hline iChao1 & 85.8 & 4.6 & 81.0 & 101.7 & 92.1 & & & & & \\
\hline Chao2 & & & & & & 100.4 & 10.8 & 87.4 & 133.3 & 78.7 \\
\hline Chao2-bc & & & & & & 98.5 & 9.9 & 86.6 & 128.7 & 80.2 \\
\hline iChao2 & & & & & & 103.2 & 7.8 & 92.1 & 123.8 & 76.6 \\
\hline $\mathrm{ACE}$ & 95.3 & 7.6 & 85.8 & 118.0 & 82.9 & & & & & \\
\hline ICE & & & & & & 118.4 & 15.3 & 97.9 & 161.2 & 66.7 \\
\hline First-order jackknife & 95.0 & 5.7 & 87.2 & 110.3 & 83.2 & 105.9 & 7.3 & 94.9 & 124.5 & 74.6 \\
\hline Second-order jackknife & 92.0 & 9.8 & 82.5 & 127.4 & 85.9 & 115.9 & 12.7 & 98.2 & 150.0 & 68.2 \\
\hline \multicolumn{11}{|l|}{ Upper } \\
\hline Homogeneous Model & 58.1 & 2.6 & 55.3 & 66.8 & 92.9 & 62.5 & 4.3 & 57.3 & 75.7 & 86.4 \\
\hline Chao1 & 68.1 & 10.4 & 57.9 & 105.3 & 79.3 & & & & & \\
\hline Chao1-bc & 65.1 & 8.2 & 57.1 & 94.6 & 82.9 & & & & & \\
\hline iChao1 & 70.6 & 7.6 & 61.0 & 93.2 & 76.5 & & & & & \\
\hline Chao2 & & & & & & 84.0 & 19.2 & 63.5 & 148.7 & 64.3 \\
\hline Chao2-bc & & & & & & 78.4 & 15.1 & 62.0 & 128.6 & 68.9 \\
\hline iChao2 & & & & & & 91.2 & 13.6 & 72.5 & 128.5 & 59.2 \\
\hline $\mathrm{ACE}$ & 65.4 & 6.6 & 58.0 & 86.5 & 82.6 & & & & & \\
\hline ICE & & & & & & 77.9 & 11.8 & 63.6 & 113.7 & 69.3 \\
\hline First-order jackknife & 67.0 & 5.1 & 60.2 & 81.3 & & 72.9 & 6.2 & 64.2 & 89.2 & 74.0 \\
\hline Second-order jackknife & 74.0 & 8.8 & 62.7 & 99.7 & & 85.9 & 10.6 & 70.9 & 114.3 & 62.9 \\
\hline \multicolumn{11}{|l|}{ Ground-Upper } \\
\hline Homogeneous Model & 94.6 & 3.4 & 90.6 & 105.0 & 93.0 & 100.2 & 5.1 & 93.5 & 114.9 & 87.8 \\
\hline Chao1 & 98.1 & 6.3 & 91.3 & 118.9 & 89.7 & & & & & \\
\hline Chao1-bc & 97.0 & 5.7 & 90.9 & 116.1 & 90.7 & & & & & \\
\hline iChao1 & 98.1 & 6.3 & 91.3 & 118.9 & 89.7 & & & & & \\
\hline Chao2 & & & & & & 107.9 & 10.2 & 95.7 & 139.2 & 81.6 \\
\hline Chao2-bc & & & & & & 106.0 & 9.3 & 94.9 & 134.9 & 83.0 \\
\hline iChao2 & & & & & & 108.3 & 14.8 & 93.6 & 161.0 & \\
\hline $\mathrm{ACE}$ & 105.1 & 7.9 & 95.2 & 128.5 & 83.7 & & & & & \\
\hline $\mathrm{ICE}$ & & & & & & 121.7 & 13.4 & 103.9 & 159.6 & 72.3 \\
\hline First-order jackknife & 106.0 & 6.0 & 97.5 & 122.0 & 83.0 & 114.0 & 7.2 & 103.2 & 132.3 & 77.2 \\
\hline Second-order jackknife & 108.0 & 10.4 & 95.7 & 140.1 & 81.5 & 123.0 & 12.5 & 105.7 & 156.9 & 71.5 \\
\hline
\end{tabular}

For details on estimators, see iNext package (Hsieh et al., 2016). 
exclusively or occasionally live there and for which the cave represents an important habitat (Culver et al., 2012). The pitfall trapping method has been widely used in speleobiological studies. The present research is a pilot study towards the optimization of pitfall trapping in caves with the aim of providing an optimally complete data set along with minimal damage to the subterranean community.

The greater species richness clearly indicates in favor of the combined, upper-ground sampling approach, with about $10 \%$ additional taxa over single-set-alone sampling. On the one hand, this is a consequence of increased sampling effort by doubling the number of sampling sites in comparison with traditional sampling. However, this alone does not explain the outcomes. On the other hand, this may also be the consequence of greater microhabitat heterogeneity. Thus, the suggested combined-set sampling provides a more complete inventory than traditional sampling. This could mean a shortage in inventories from caves where only ground pitfall trapping has been applied, and the apparent absence of many species in caves could, in fact, be a methodological artifact. Moreover, since many important cave microhabitats have not been sampled, this could be a plausible reason behind why some species are missing in traditional pitfall sampling. Zguba jama is, on average, of a humansized cross-section. It is assumed that in larger caves the contribution of the upper pitfall traps to the species richness could be even greater.

Both incidence-based and abundance-based approaches indicate that taking into account the combined ground-upper pitfall trap set suggests the existence of more species and yields greater estimates of total species richness in a cave than using the ground pitfall trap set alone. Owing to the mostly greater incidence-based estimates, this approach is strongly recommended over the abundance approach in biodiversity studies of subterranean habitats (see Novak et al., 2012). This is in agreement with Gotelli and Colwell's (2011) argument that, although individuals contain biodiversity "information", i.e., the species identity, it is the samples that represent the statistically independent replicates for analysis.

Species richness is very difficult to measure (Gotelli \& Collwell, 2011). Species composition of the assemblage changes over time, and is in some places considerably influenced by migration (Żmihorski, 2013). In caves this especially holds true for trogloxenes and troglophiles, since most of them do not live exclusively in subterranean habitats, a pattern that causes substantial variation in their communities over the year (Di Russo et al., 1999; Novak et al., 2012; Tobin et al., 2013). Seasonal migrations of troglobionts have also been documented between caves and adjacent habitats inaccessible to humans (Juberthie, 1967; Uéno, 1987; Crouau-Roy et al., 1992; Lencioni et al., 2010; Novak et al., 2012; Tobin et al., 2013; Mammola et al., 2015, 2016). Chao et al. (2009) suggest that it is reasonable to set $95 \%$ of species as a practical limit in biological surveys. For the ground-upper pitfall sampling method, the necessary sampling effort, based on Chao 1, suggests
$95 \%$ of species, if approximately twice as many samples were collected. In our case, we could reach this number of samples within two years.

The ground traps provided significantly greater number of individuals, richness and diversity, and are therefore of fundamental importance to biological inventory in caves. On the other hand, the upper traps provided evidence of one-tenth of those species not recorded by ground traps, in this way considerably completing the inventory.

Additionally, we showed that to study faunal diversity and dynamics, sampling performed by frequent placement of traps for a short period (e.g., two days) is sufficiently effective to enable credible biodiversity consideration and simultaneously diminishes the threat of oversampling or even depletion of populations (Novak et al., 2012), which are often insularly distributed in subterranean habitats (Culver \& Pipan, 2009). This can become especially important in areas with highly diverse and vulnerable species-especially endemic species, where conflicts between fauna exploration and conservation represent an ongoing nuisance (e.g., Culver \& Sket, 2000; Reboleira et al., 2011; Souza Silva \& Ferreira, 2016).

In most biological sciences, invasive sampling cannot be avoided, therefore, optimization of sampling methods is required to balance conservation interests and new knowledge acquirement with minimal disturbance. Sampling efficiency is a key component in the design of biodiversity inventories (New, 1998; Oliver et al., 1999). Incomplete sampling as well as sampling bias can crucially affect conservation strategies (Zagmajster et al., 2010). Therefore, a combination of varied methods of studying cave fauna is also highly recommended (Hunt \& Millar, 2001). Even variation within the same method can provide significant improvement in data collection outcomes.

\section{CONCLUSIONS}

Much more attention should be given to the inclusion of as many microhabitats as possible within caves to provide more credible estimates of biodiversity in caves in the future (see Brennan et al., 1999). This is especially true in cave sections with considerably varying microhabitat conditions, for example the entrance section. More complete data on biodiversity would be welcomed in further studies of caves to estimate the overall missed biodiversity with greater accuracy. If we agree that $95 \%$ of the total estimated species is an appropriate basis for relevant study of fauna in caves, and that pitfall sampling remains an important sampling method, the ground-upper pitfall setting fulfills this goal significantly better in comparison to traditional sampling. However, research in morphologically different caves, including those with high ceilings, is required. Despite this drawback and the much greater, but still reasonable sampling effort required, the suggested method is a promising way to standardize the kind of credible biological data collection that would improve biodiversity and ecological studies in caves. 


\section{ACKNOWLEDGEMENTS}

We are indebted to David C. Culver for helpful discussion and comments on the initial version of the manuscript, and him and Michelle Gadpaille for the linguistic improvement of the text. We thank Giulio Gardini, Andrej Mock, and Marko Lukić for identification of Pseudoscorpiones, Diplopoda and Collembola, respectively, and to Petra Gostinčar for preparing the map of the study site. We are grateful to Stefano Mammola and two anonymous reviewers for their insightful comments and suggestions. Peter Kozel also acknowledge the Slovenian Research Agency, Program for Young Researchers, for providing a research grant.

\section{REFERENCES}

Boutin C., 2004 - Organisms: classification. In: Gunn J. (Ed.), Encyclopedia of Cave and Karst Science. Fitzroy Dearborn, New York, p. 548-549.

Bregović P. \& Zagmajster M., 2016 - Understanding hotspots within a global hotspot - identifying the drivers of regional species richness patterns in terrestrial subterranean habitats. Insect Conservation and Diversity, 9 (4): 268-281.

https://doi.org/10.1111/icad.12164

Brose U., Martinez N.D. \& Williams R.J., 2003 Estimating species richness: Sensitivity to sample coverage and insensitivity to spatial patterns. Ecology, 84 (9): 2364-2377.

https://doi.org/10.1890/02-0558

Cardoso P., 2012 - Diversity and community assembly patterns of epigean vs. troglobiont spiders in the Iberian Peninsula. International Journal of Speleology, 41(1): 83-94.

https://doi.org/10.5038/1827-806X.41.1.9

Campbell J.W., Woods M., Ball H.L., Pirkle R.S., Carey V. \& Ray C.H., 2011 - Terrestrial macroinvertebrates captured with a baited ramp-pitfall trap from five limestone caves in North Alabama and Georgia (USA) and their association with soil organic matter. Journal of Natural History, 45: 2645-2659.

https://doi.org/10.1080/00222933.2011.597884

Chao A., Colwell R.K., Lin C.W. \& Gotelli N.J., 2009 Sufficient sampling for asymptotic minimum species richness estimators. Ecology, 90 (4): 1125-1133. https://doi.org/10.1890/07-2147.1

Chao A., Gotelli N.J., Hsieh T.C., Sander E.L., Ma K.H., Colwell R.K. \& Ellison A.M., 2014 - Rarefaction and extrapolation with Hill numbers: a framework for sampling and estimation in species diversity studies. Ecological Monographs, 84 (1): 45-67. https://doi.org/10.1890/13-0133.1

Chao A. \& Jost L., 2012 - Coverage-based rarefaction and extrapolation: standardizing samples by completeness rather than size. Ecology, 93 (12): 2533-2547. https://doi.org/10.1890/11-1952.1

Chao A., Ma K.H., Hsieh T.C. \& Chiu C.H., 2016a SpadeR: Species-Richness Prediction and Diversity Estimation with $\mathrm{R}$. R package version 0.1.1. https://CRAN.R-project.org/package $=$ SpadeR

Chao A., Ma K.H. \& Hsieh T.C., 2016b - User's Guide for iNEXT Online: Software for Interpolation and Extrapolation of Species Diversity.

http://chao.stat.nthu.edu.tw/wordpress/wp-content/ uploads/software/iNEXTOnline UserGuide.pdf
Christman M.C., Culver D.C., Madden M. \& White D., 2005 - Patterns of endemism of the eastern North American cave fauna. Journal of Biogeography, 32: 1441-1452. https://doi.org/10.1111/j.1365-2699.2005.01263.x

Crouau-Roy B., Crouau Y. \& Source C.F., 1992 Dynamic and temporal structure of the Troglobitic beetle Speonomus hydrophilus (Coleoptera: Bathysciinae). Ecography, 15 (1): 12-18.

https://doi.org/10.1111/j.1600-0587.1992.tb00002.x

Culver D.C. \& Pipan T., 2009 - The biology of caves and other subterranean habitats, Oxford University Press, New York, 256 p.

Culver D.C. \& Pipan T., 2013 - Subterranean ecosystems. In: Levin S.A. (Ed.), Encyclopedia of Biodiversity $\left(2^{\text {nd }}\right.$ Ed.). Academic Press, Massachusetts, p. 49-62.

https://doi.org/10.1016/B978-0-12-384719-5.00224-0

Culver D.C. \& Pipan, T., 2014 - Shallow subterranean habitats. Ecology, evolution, and conservation. Oxford University Press, Oxford, 288 p.

https://doi.org/10.1093/acprof:oso/9780199646173. $\underline{001.0001}$

Culver D.C. \& Sket, B., 2000 - Hotspots of subterranean biodiversity in caves and wells. Journal of Caves and Karst Studies, 62 (1): 11-17.

Culver D.C., Trontelj P., Zagmajster M. \& Pipan T., 2013 - Paving the way for standardized and comparable subterranean biodiversity studies. Subterranean Biology, 10: 43-50.

https://doi.org/10.3897/subtbiol.10.4759

Deharveng L., Dalens H., Drugmand D., Simon-Benito J.C., da Gama M.M., Sousa P., Gers C. \& Bedos A., 2000 - Endemism mapping and biodiversity conservation in Western Europe: An arthropod perspective. Belgian Journal of Entomology, 2 (1): 59-75.

Di Russo C., Carchini G., Rampini M., Lucarelli M. \& Subordoni V., 1999 - Long term stability of a terrestrial cave community. International Journal of Speleology, 26 (1-2): 75-88. https://doi.org/10.5038/1827-806X.26.1.7

Dole-Olivier M.J., Malard F., Martin P., Levébure T. \& Gibert J., 2009 - Relationships between environmental gradients and groundwater biodiversity at a regional scale. Freshwater Biology, 54: 797-813.

https://doi.org/10.1111/j.1365-2427.2009.02184.x

Giachino P.M. \& Vailati D., 2010 - The subterranean environment: hypogean life, concepts and collecting techniques. World Biodiversity Association, Verona, $132 \mathrm{p}$.

Gotelli N.J. \& Colwell R.K., 2011 - Estimating species richness. In: Magurran A.E. \& McGill B.J. (Eds.), Frontiers in measuring biodiversity. Oxford University Press, New York, p. 39-54.

Henen B.T., 2016 - Do scientific collecting and conservation conflict? Herpetological Conservation and Biology, 11 (1): 13-18.

Howarth F.G., 1981 - The conservation of cave invertebrates. In: Mylroie J.E. (Ed.), Proceedings of the First International Cave Management Symposium. Murray, Kentucky, p. 57-63.

Howarth F.G., 1993 - High-stress subterranean habitats and evolutionary change in cave-inhabiting arthropods. The American Naturalist, 142: S65-S77.

Hsieh T.C., Ma K.H. \& Chao A., 2016 - iNEXT: iNterpolation and EXTrapolation for species diversity. $\mathrm{R}$ package version 2.0.12. http://chao.stat.nthu.edu.tw/blog/software-download Juberthie C., 1969 - Relation entre le climat, le microclimat et Aphaenops cerberus dans la grotte de SainteCatherine (Ariége). Annales de Spéleologie, 24: 75-104. 
Krauss J., Bommarco R., Guardiola M., Heikkinen R.K., Helm A., Kuussaari M., Lindborg R., Öckinger E., Pärtel M., Pino J., Pöyry J., Raatikainen K.M., Sang A., Stefanescu C., Teder T., Zobel M. \& Steffan-Dewenter I., 2010 - Habitat fragmentation causes immediate and time-delayed biodiversity loss at different trophic levels. Ecology Letters, 13 (5): 597-605.

https://doi.org/10.1111/j.1461-0248.2010.01457.x

Lencioni V., Bernabo P. \& Latella L., 2010 - Cold resistance in two species of cave-dwelling beetles (Coleoptera: Cholevidae). Journal of Thermal Biology, 35 (7): 354-359.

https://doi.org/10.1016/j.jtherbio.2010.07.004

Magurran A.E., 1996 - Ecological diversity and its measurement. Princeton University, Princeton, 179 p.

Malard F., Boutin C., Camacho A.I., Ferreira D., Michel G., Sket B. \& Stoch F., 2009 - Diversity patterns of stygobiotic crustaceans across multiple spatial scales in western Europe. Freshwater Biology 54: 756-776.

https://doi.org/10.1111/j.1365-2427.2009.02180.x

Mammola S. \& Isaia M., 2016 - The ecological niche of a specialized subterranean spider. Invertebrate Biology, 135 (1): 20-30.

https://doi.org/10.1111/ivb.12113

Mammola S., Giachino P.M., Piano E., Jones A., Barberis M., Badino G. \& Isaia M., 2016 - Ecology and sampling techniques of an understudied subterranean habitat: the Milieu Souterrain Superficiel (MSS). The Science of Nature, 103 (11-12): 88.

https://doi.org/10.1007/s00114-016-1413-9

Mammola S., Piano E., Giachino P.M. \& Isaia M., 2015 - Seasonal dynamics and micro-climatic preference of two Alpine endemic hypogean beetles. International Journal of Speleology, 44 (3); 239-249.

https://doi.org/10.5038/1827-806X.44.3.3

Mammola S., Piano E. \& Isaia M., 2016 - Step back! Niche dynamics in cave-dwelling predators. Acta Oecologica, 75 (2016): 35-42.

https://doi.org/10.1016/j.actao.2016.06.011

Minteer B.A., Collins J.P., Love K.E. \& Puschendorf R., 2014 - Avoiding (Re) extinction. Science, 344: 260-261. https://doi.org/10.1126/science.1250953

Mooney H. \& Mace G., 2009 - Biodiversity policy challenges. Science, 325 (5947): 1474.

https://doi.org/10.1126/science.1180935

Mora C., Tittensor D.P., Adl S., Simpson A.G.B. \& Worm B., 2011 - How many species are there on Earth and in the ocean? PLoS Biology, 9 (8), e1001127. https://doi.org/10.1371/journal.pbio.1001127

New T.R., 1998 - Invertebrate surveys for conservation. Oxford University Press, Oxford, 256 p.

Niemiller M.L. \& Zigler K.S., 2013 - Patterns of cave biodiversity and endemism in the Appalachians and Interior Plateau of Tennessee, USA. PLoS ONE, 8 (5), e64177.

https://doi.org/10.1371/journal.pone.0064177

Novak T., Perc M., Lipovšek S. \& Janžekovič F., 2012 Duality of terrestrial subterranean fauna. International Journal of Speleology, 41 (2): 181-188.

https://doi.org/10.5038/1827-806X.41.2.5

Novak T., Sambol J. \& Janžekovič F., 2004 - Faunal dynamics in the Železna jama cave. Acta Carsologica, 33, 249-267.

Novak T., Tkavc T., Kuntner M., Arnett A.E., Lipovšek Delakorda S., Perc M. \& Janžekovič F., 2010 - Niche partitioning in orbweaving spiders Meta menardi and Metellina merianae (Tetragnathidae). Acta Oecologica, 36: 522-529.

https://doi.org/10.1016/j.actao.2010.07.005
Oksanen J., Blanchet G.F., Kindt R., Legendre P., Minchin P.R., O’Hara R.B., Simpson G.L., Solymos P., Stevens M.H.H. \& Wagner H., 2016 - Vegan: community ecology package. $\mathrm{R}$ package version 2.3-5.

https://CRAN.R-project.org/package=vegan

Oliver I., Dangerfield J.M. \& York A., 1999 - When and how to conduct a biodiversity assessment of terrestrial invertebrates. In: Ponder W. \& Lunney D. (Eds.), The other 99\%. The conservation and biodiversity of invertebrates. Transactions of the Royal Zoological Society of New South Wales, p. 8-18.

Peck S.B., 1995 - The cave fauna of Alabama: Part II: the insects. Bulletin of the National Speleological Society, 57: 1-19.

Poulson T.L. \& Culver D.C., 1968 - Diversity in terrestrial cave communities. Ecology, 50 (1): 153-158. https://doi.org/10.2307/1934678

$\mathrm{R}$ Development Core Team, 2016 - R: A Language and environment for statistical computing. $\mathrm{R}$ Foundation for Statistical Computing, Vienna, Austria. https://www.R-project.org

Racoviță E.G., 1907 - Essai sur les problemes biospéologiques. Archives de Zoologie Expérimentale et Générale (Biospéol. I), 4e ser., 6: 371-488.

Racovitza G., 1983 - Sur les relations dynamiques entre le milieu souterrain superficiel et milieu cavernicole. Mémoires de Biospéologie, 10: 85-89.

Reboleira A.S.P.S., Borges P.A.V., Gonçalves F., Serrano A.R.M. \& Oromi P., 2011 - The subterranean fauna of a biodiversity hotspot region - Portugal: an overview and its conservation. International Journal of Speleology, 40 (1): 23-37.

https://doi.org/10.5038/1827-806X.40.1.4

Sabu T.K. \& Shiju R.T., 2010 - Efficacy of pitfall trapping, Winkler and Berlese extraction methods for measuring ground-dwelling arthropods in moist deciduous forests in the Western Ghats. Journal of Insect Science, 10 (98), 1-17. https://doi.org/10.1673/031.010.9801

Sager P.E. \& Hasler A.D., 1969 - Species diversity in lacustrine phytoplankton. I. The components of the index of diversity from Shannon's formula. The American Naturalist, 103: 51-59. https://doi.org/10.1086/282581

Schiner J.R., 1854 - Fauna der Adelsberger-, Lueger-, \& Magdalenen Grotte. In: A. Schmidl (Ed.), Zur Höhlenkunde des Karstes. Die Grotten und Höhlen von Adelsberg, Lueg, Planina und Laas. Wien: Braumüller: 231-272.

Sharratt N.J., Picker M.D. \& Samways M.J., 2000 - The invertebrate fauna of the sandstone caves of the Cape Peninsula (South Africa): patterns of endemism and conservation priorities. Biodiversity \& Conservation, 9: 107-143. https://doi.org/10.1023/A:1008968518058

Shaw P. \& Davis M., 1999 - Invertebrates from caves on Vancouver Island. In: Darling I.M. (Ed.), Proceedings of a conference on the biology and management of species and habitats at risk. Ministry of Environment, Land and Parks, Victoria, BC and University College of Cariboo, Kamloops BC, p. 121-124.

Souza Silva M.S. \& Ferreira R.L., 2016 - The first two hotspots of subterranean biodiversity in South Americ. Subterranean Biology, 19: 1-21.

https://doi.org/10.3897/subtbiol.19.8207

Slaney D.P. \& Weinstein P., 1996 - Leaf litter traps for sampling orthopteroid insects in tropical caves. Journal of Orthoptera Research, 5: 51-52.

Sket B., 2012 - Diversity patterns in the Dinaric karst. In: White W.B. \& Culver D.C. (Eds.), Encyclopaedia of caves ( $2^{\text {nd }}$ Ed.), p. 228-238.

https://doi.org/10.1016/B978-0-12-383832-2.00031-1 
Šebela S., 1994 - The caves Jama na poti and Zguba jama. Acta Carsologica, 23: 233-243.

Tista M. \& Fiedler K., 2011 - How to evaluate and reduce sampling effort for ants. Journal of Insect Conservation, 15: 547-559.

https://doi.org/10.1007/s10841-010-9350-y

Tobin B.W., Hutchins B.T. \& Schwartz B.F., 2013 - Spatial and temporal changes in invertebrate assemblage structure from the entrance to deep-cave zone of a temperate marble cave. International Journal of Speleology, 42 (3): 203-214.

https://doi.org/10.5038/1827-806X.42.3.4

Trontelj P., Douady C.J., Fišer C., Gibert J., Gorički Š., Lefébure T., Sket B. \& Zakšek V., 2009 - A molecular test for cryptic diversity in groundwater: how large are the ranges of macro-stygobionts? Freshwater Biology, 54: $727-744$.

https://doi.org/10.1111/j.1365-2427.2007.01877.x

Uéno S.I., 1987 - The derivation of terrestrial cave animals. Zoological Science, 4: 593-606.

Vandel A., 1965 - Biospeleology, the Biology of Cavernicolous Animals. Pergamon, Oxford, 524 p.

Ward D.F., New T.R. \& Yen A.L., 2001 - Effects of pitfall trap spacing on the abundance, richness and composition of invertebrate catches. Journal of Insect Conservation, 5: 47-53. https://doi.org/10.1023/A:1011317423622
Weinstein P. \& Slaney D., 1995 - Invertebrate faunal survey of Rope Ladder cave, Northern Queensland: a comparative study of sampling methods. Journal of Australian Entomological Society, 34: 233-236. https://doi.org/10.1111/j.1440-6055.1995. tb01329.x

Zagmajster M., Culver D.C. \& Sket B., 2008 - Species richness patterns of obligate subterranean beetles (Insecta: Coleoptera) in a global biodiversity hotspot effect of scale and sampling intensity. Diversity and Distributions, 14: 95-105.

https://doi.org/10.1111/j.1472-4642.2007.00423.x

Zagmajster M., Culver D.C., Christman M. \& Sket B., 2010 - Evaluating the sampling bias in pattern of subterranean species richness: combining approaches. Biodiversity Conservation, 19 (11): 3035-3048. https://doi.org/10.1007/s10531-010-9873-2

Zuur A.F., Ieno E.N. \& Elphick S.C., 2010 - A protocol for data exploration to avoid common statistical problems. Methods in Ecology and Evolution, 1 (1): 3-14. https://doi.org/10.1111/j.2041-210X.2009.00001.x

Żmihorski M., Sienkiewicz P. \& Tryjanowski P., 2013 - Never ending story: a lesson in using sampling efficiency methods with ground beetles. Journal of Insect Conservation, 17: 333-337. https://doi.org/10.1007/s10841-012-9514-Z 